\title{
Concentration of 2-Phenylphenol by Organoclays from Aqueous Sucrose Solution
}

\author{
Yoko SEKI, Yusuke IDE, Tomohiko OKADA, and Makoto OGAWA* \\ Department of Earth Sciences, Waseda University, Nishiwaseda 1-6-1, Shinjuku-ku, Tokyo 169-8050, \\ Japan.
}

Corresponding author. E-mail: makoto@waseda.jp; Fax: +81-3-3207-4950

\begin{abstract}
The adsorption of 2-phenylphenol, which is an antifungal agent, onto organically modified clay from aqueous sucrose solution was investigated. 2-Phenylphenol was effectively adsorbed on neostigminemodified smectites and octadecyltrimethylammonium modified smectites even in the presence of sucrose in the starting aqueous solution. Two smectites (a natural montmorillonite, Kunipia F, and a synthetic saponite, Sumecton SA) were used to find clay minerals with lower layer charge density gave larger adsorption capacity for 2-phenylphenol. The result showed the potential application of the organically modified clays to remove 2-phenylphenol from orange extracts.
\end{abstract}

\section{Keywords}

molecular recognition; smectite; organoclay; 2-phenylphenol 
Graphic abstract

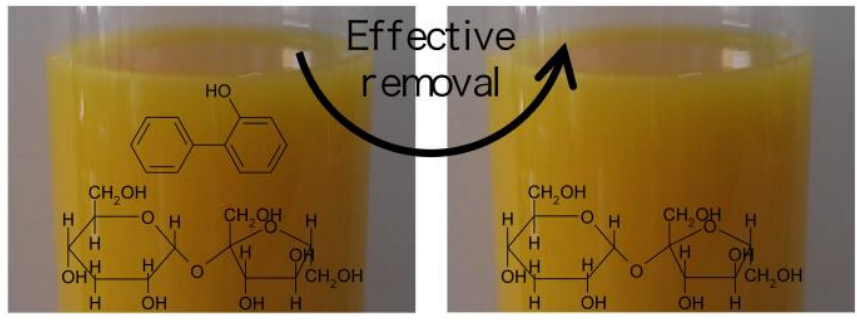




\section{Introduction}

The concentration of certain molecular species from environments by the adsorption onto solids is a topic of a wide range of scientific and practical interests such as the removal of toxic compounds and the concentration of the noble elements. Since the target species to be concentrated, noble metals in sea water and herbicide and pesticide in ground water for example, are normally mixed with other species, selective adsorption of target species from the mixtures are prerequisites for the practical application. Several inorganic-organic hybrid materials have been designed for this purpose (Lagaly, 1981; Barrer, 1989; Ogawa and Kuroda, 1997; Xu et al., 1997; Stein et al., 2000; Okada et al., 2012; Okada et al., 2014), in addition to the well established such nanoporous materials as zeolites with molecular sieving effects (Breck, 1974; Barrer 1978). We have recently achieved the selective (molecular recognitive) adsorption of certain kind of organic compounds on organically modified layered titanate and silicate from aqueous mixtures (Wei and Nakato, 2006; Ide and Ogawa, 2007; Ide et al., 2011) and molecular recognitive photocatalytic decomposition on layered titanates (Ide et al., 2010). These successes motivated us to study selective adsorption from aqueous mixtures for environmental purification and food safety.

In this article, 2-phenylphenol (which is also known as 2-hydroxybiphenyl and named 2PP in this study), a well-known antifungal agent used for oranges, was concentrated from aqueous sucrose solutions using organically-modified smectites (Tayama et al., 1989; Cheng et al., 2005). On site removal of $2 \mathrm{PP}$ would be a way to improve the safety of fresh orange juice. In the previous study, we successfully concentrated 2PP from aqueous solutions using organically-pillared clays (Seki and Ogawa, 2010) with appropriate interlayer organic cation. In this study, $2 \mathrm{PP}$ adsorption from aqueous sucrose solutions was investigated. Organically-modified smectites were used because of the tunable adsorption characteristics thanks to the materials' variation (Lee et al., 1989; Lawrence et al., 1998; Okada and Ogawa, 2003; Okada et al., 2004; Okada and Ogawa, 2004; Okada et al., 2005; Okada et al., 2010). Smectites are layered clay minerals with negatively-charged layers and charge-compensating interlayer cations (Theng, 1974; van Olphen, 1977) have possible applications as adsorbents for 
radioactive ions in nuclear wastes (Kozai et al., 1993) as well as heavy metals (Mercier and Detellier, 1995), and photo/electro functions (Ogawa and Kuroda, 1995). When interlayer cations are replaced with organoammonium cations, the surface properties can be modified to enhance the sorption of various nonionic organic species (Jordan, 1949; Barrer and Perry, 1961a, 1961b; Barrer, 1978; Ogawa et al., 1994; Jaynes and Vance, 1999; Chun et al., 2003; Hayashi, et al., 2003; Nir et al., 2006; Seki and Ogawa, 2010). We have recently shown the possible roles of interlayer cations and layer charge in controlling adsorption capacity (Seki and Ogawa, 2010). In this study, two pillared and one organophilic organically-modified clay minerals were used to concentrate $2 \mathrm{PP}$ from aqueous sucrose solutions. Octadecyltrimethylammonium-exchanged montmorillonite was used as an example of organophilic clay. Neostigmine-smectites were used as adsorbents because they were suitable 2PP sorbents according to the previous investigation (Seki and Ogawa, 2010). The effects of sucrose in water on the 2PP adsorption are discussed in this paper.

\section{Experimental}

\subsection{Reagents and materials}

Natural Na-montmorillonite (Kunipia F obtained from Kunimine Ind. Co., Japan; hereafter abbreviated as KF; $\left.\left.\left(\mathrm{Na}_{0.53} \mathrm{Ca}_{0.09}\right)^{0.71+}\left[\mathrm{Al}_{3.28} \mathrm{Fe}_{0.31} \mathrm{Mg}_{0.43}\right)\left(\mathrm{Si}_{7.65} \mathrm{Al}_{0.35}\right) \mathrm{O}_{20}(\mathrm{OH})_{4}\right]^{0.71-}\right)$ and a synthetic saponite (Sumecton SA from Kunimine Ind. Co., Japan; hereafter abbreviated as SA; $\left.\left.\left(\mathrm{Na}_{0.49} \mathrm{Ca}_{0.14}\right)^{0.77+}\left[\mathrm{Mg}_{5.97} \mathrm{Al}_{0.03}\right)\left(\mathrm{Si}_{7.20} \mathrm{Al}_{0.80}\right) \mathrm{O}_{20}(\mathrm{OH})_{4}\right]^{0.77-}\right)$ were used. Neostigmine bromide $\left(\mathrm{CH}_{3}\right)_{3} \mathrm{~N}^{+}\left(\mathrm{C}_{6} \mathrm{H}_{4}\right) \mathrm{CO}_{2} \mathrm{~N}\left(\mathrm{CH}_{3}\right)_{2} \mathrm{Br}^{-}$(abbreviated as $\mathrm{CONH}$ ) and octadecyltrimethylammonium (abbreviated as $\mathrm{C}_{18}$ TMA) chloride were purchased from Tokyo Kasei Ind. Co. and used as received. The molecular structures of $2 \mathrm{PP}, \mathrm{CONH}$, and $\mathrm{C}_{18} \mathrm{TMA}$ are shown in Figure 1.

\subsection{Preparation of adsorbents}

Organoammonium-clays were prepared from $\mathrm{KF}$ and $\mathrm{SA}$ by cation exchange in aqueous solutions as previously reported (Ogawa et al., 1993; Ogawa et al., 1995 Seki and Ogawa, 2010). Adsorbed organic cation amounts of $111 \mathrm{meq} / 100 \mathrm{~g}$ for $\mathrm{C}_{18}$ TMA-KF, $115 \mathrm{meq} / 100 \mathrm{~g}$ for 
CONH-KF, and $73 \mathrm{meq} / 100 \mathrm{~g}$ for CONH-SA were determined from the organic carbon contents, which confirmed quantitative cation exchange. The basal spacing of $2.17 \mathrm{~nm}$ for $\mathrm{C}_{18} \mathrm{TMA}-\mathrm{KF}$ indicates a pseudo-trimolecular arrangement of $\mathrm{C}_{18}$ TMA (Ogawa et al., 1993; Ogawa et al., 1995). On the other hand, the basal spacings of CONH-KF and CONH-SA were 1.73 and $1.51 \mathrm{~nm}$, respectively, which is indicative of the microporous structures (organic pillared clay) as reported previously (Seki and Ogawa, 2010). Figure 2 shows the nitrogen adsorption/desorption isotherms of KF and SA before and after the pillaring. It is not straight forward to derive microporous structure from the isotherms due to the expected complex geometry as well as the difficulty to remove adsorbed water completely. In addition, due to the nature of finite particles, the contribution of external surface on the BET surface area is not negligible (Michot, and Villiéras, 2013). From the nitrogen adsorption isotherms, BET surface area was determined and the values (CONH-SA: $144 \mathrm{~m}^{2} \mathrm{~g}^{-1}$ and CONH-KF: $14 \mathrm{~m}^{2} \mathrm{~g}^{-1}$ ) are slightly larger than those of original clay minerals (SA: $112 \mathrm{~m}^{2} \mathrm{~g}^{-1}$ and KF: $13 \mathrm{~m}^{2} \mathrm{~g}^{-1}$ ).

\subsection{Adsorption tests}

Adsorption of 2PP from $15 \mathrm{mM}(5.13 \mathrm{~g} / \mathrm{L})$ aqueous sucrose solutions was conducted as follows: adsorbents $(25 \mathrm{mg}$ ) were reacted with $50 \mathrm{~mL}$ of aqueous $2 \mathrm{PP}$ solution in $50 \mathrm{~mL}$-glass vessels for 1 day at room temperature in the dark. Initial concentration of $2 \mathrm{PP}$ was $0.05-1.0 \mathrm{mM}(0.085-0.17 \mathrm{~g} / \mathrm{L})$. Blank samples without adsorbents, were also prepared to estimate vaporization losses and the adsorption on the glass vessel. After the adsorbents were separated by centrifugation, the concentration of the remaining 2PP in supernatant was determined by UV absorption spectroscopy (absorption $\lambda_{\max }$ of $2 \mathrm{PP}$ at $282 \mathrm{~nm}$ ). Adsorption isotherms were obtained by plotting the adsorbed amounts of $2 \mathrm{PP}$ versus the equilibrium concentrations.

\section{Insert Fig.s 1 and 2}

\section{Results and discussion}


The adsorption isotherms of 2PP from water on the CONH-SA and KF were reported previously

(Seki and Ogawa, 2010). In the present study, the adsorption isotherms of 2PP from water and aqueous sucrose solution on the CONH-SA and KF were obtained as shown in Figure 3. Adsorption isotherms of 2PP from water and aqueous sucrose solutions for CONH-SA and CONH-SA were fitted to the Langmuir equation $\left(1 / W=1 / W_{\mathrm{s}}+\left(1 / a W_{\mathrm{s}}\right)(1 / C)\right.$ by plotting $1 / C$ versus $\left.1 / W_{\mathrm{s}}\right)$, where $W$ is $2 \mathrm{PP}$ adsorbed to the organoclays and $C$ is equilibrium 2PP concentration (Figure 3). The sucrose did not significantly affect $2 \mathrm{PP}$ adsorption. The adsorption constant $(a)$, the amounts of $2 \mathrm{PP}$ adsorbed as a monolayer $\left(W_{\mathrm{s}}\right)$, and the $R^{2}$ values (measure of linearity) were determined for each isotherm. A large affinity between the $\mathrm{CONH}$ aromatic ring and the $2 \mathrm{PP}$ aromatic ring is thought to occur. The $2 \mathrm{PP}$ adsorption constant $(a)$ values of 20.0 for CONH-KF with sucrose and 20.7 without sucrose (Table 1) were almost the same. The 45.3 adsorption constant (a) value for 2PP adsorption to CONH-SA from sucrose was larger than the 36.1 value from water. This means that $\mathrm{CONH} / 2 \mathrm{PP}$ interactions were strong enough for effective adsorption even in the presence of sucrose.

\section{Insert Fig. 3 and Table 1}

Monolayer 2PP adsorption to CONH-KF was $0.041 \mathrm{~g} / \mathrm{g}$ of clay (Table 1 ), which was not affected by sucrose. Monolayer 2PP adsorption to CONH-SA was $0.067 \mathrm{~g} / \mathrm{g}$ with sucrose and $0.062 \mathrm{~g} / \mathrm{g}$ without sucrose. Thus, 2PP concentration from aqueous sucrose solution was more efficient than that from 2PP solution. Though this phenomenon is presently difficult to explain, differences of the $2 \mathrm{PP}$ solubility in water and in sucrose solution might be concerned. While the presence of sucrose resulted in increasing monolayer 2PP adsorption on CONH-SA, the adsorbed 2PP amount was smaller when the initial concentration of $2 \mathrm{PP}$ was higher (Figure 3$)$. The correlation coefficient of Langmuir equation $\left(\mathrm{R}^{2}\right.$ in Table 1) was smaller in the case of co-existence of sucrose $(0.9552$ without sucrose and 0.9327 with sucrose). Generally, on partitioning between adsorbent and solvent, relative contribution of both 
adsorbate-solvent and adsorbate-adsorbent interactions determines the adsorption capacity. In the CONH-SA system, adsorbent-solvent interactions may be affected by the presence of sucrose in the solution to give the observed difference. Larger amounts of $2 \mathrm{PP}$ were adsorbed to CONH-SA than those to CONH-KF (Table 1 and Figure 3). One explanation is that the relatively low-layer charge saponite led to relatively larger interlayer pore volumes (Seki and Ogawa, 2010). On the other hand, the presence of sucrose did not affect the $2 \mathrm{PP}$ adsorption on $\mathrm{CONH}-\mathrm{KF}$, probably due to the smaller pore size and volume

of

CONH-KF than

CONH-SA.

The adsorption isotherms of $2 \mathrm{PP}$ onto $\mathrm{C}_{18} \mathrm{TMA}-\mathrm{KF}$ are shown in Figure 4. The $2 \mathrm{PP}$ adsorption isotherms were type C according to the Giles classification (Giles et al., 1974), where 2PP uptake resulted from partitioning. For this type of isotherm, the following equation has been proposed: $W=$ $K_{\mathrm{p}} C$, where $W, K_{\mathrm{p}}$, and $C$ denote adsorbed amount, partition coefficient, and equilibrium concentration, respectively. From this equation, a $K_{\mathrm{p}}$ value of 1.80 was determined for $2 \mathrm{PP}$ sorption to $\mathrm{C}_{18} \mathrm{TMA}-\mathrm{KF}$ with or without sucrose. The higher adsorption efficiency for $\mathrm{C}_{18} \mathrm{TMA}-\mathrm{KF}$ was shown by comparing with the adsorption isotherms on $\mathrm{CONH}$-smectites (Figure 3). These results suggest that 2PP adsorption to $\mathrm{C}_{18} \mathrm{TMA}-\mathrm{KF}$ occurred by hydrophobic interactions between $2 \mathrm{PP}$ and the alkyl chains of the interlayer $\mathrm{C}_{18}$ TMA, and the interactions play a dominant role in the $2 \mathrm{PP}$ adsorption. Accordingly, sucrose had no effect on the adsorption.

\section{Insert Fig. 4 and Fig. 5}

The removal of $2 \mathrm{PP}$ by $\mathrm{C}_{18} \mathrm{TMA}-\mathrm{KF}$ was effective with $\%$ removal values larger than $60 \%$ (Figure 5). When the initial 2PP concentration was lower than $0.085 \mathrm{~g} / \mathrm{L}(0.5 \mathrm{mM})$, more than $80 \%$ of $2 \mathrm{PP}$ adsorbed to $\mathrm{C}_{18} \mathrm{TMA}-\mathrm{KF}$. This means that the $2 \mathrm{PP}$ that remained in $1 \mathrm{~L}$ of sucrose solution after treatment with $25 \mathrm{mg}$ of $\mathrm{C}_{18} \mathrm{TMA}-\mathrm{KF}$ was $<17 \mathrm{mg}$. This value is lower than the $20 \mathrm{mg} / 50 \mathrm{~kg} / \mathrm{day} 2 \mathrm{PP}$ 
intake set by the World Health Organization. These findings motivate further study on 2PP removal from foods.

\section{Conclusions}

The antifungal agent, 2-phenylphenol, was effectively sorbed by neostigmine-modified smectites and octadecyltrimethylammonium-modifed montmorillonite from aqueous sucrose solutions. Sucrose did not affect 2-phenyphenol concentration for the organically modified montmorillonites, suggesting that the future possibility to remove toxic compounds from foods and drinks.

\section{Acknowledgments}

The work was partially supported by a Grant-in-Aid for GCOE research, Ministry of Education, Culture, Sports, Science and Technology (MEXT), Japan. Waseda University also supported us financially as a Special Research Projects (2010B-061, 2009B-077 and 2009B-370).

\section{References}

Barrer, R.M., Perry, G.S., 1961. Sorption of mixtures, and selectivity in alkylammonium montmorillonites. 1. Monomethylammonium bentonite. J. Chem. Soc. Mar., 842-849.

Barrer, R.M., Perry, G.S., 1961. Sorption of mixtures, and selectivity in alkylammonium montmorillonites .2. Tetramethylammonium montmorillonite. J. Chem. Soc. Mar., 850-858.

Barrer, R.M., 1978. Zeolites and Clay Minerals as Sorbents and Molecular Sieves. Academic Press, London.

Barrer, R.M., 1989. Shape-selective sorbents based on clay-minerals: a Review. Clays Clay Miner., 37, 385-395.

Breck, D.W., 1974. Zeolites Molecular Sieves. John Wiley, New York. 
Cheng, S.L., Wang, H.C., Yang, P.C., 2005. Acute respiratory distress syndrome and lung fibrosis after ingestion of a high dose of ortho-phenylphenol. J. Formos. Med. Assoc. 104, 585-587.

Chun, Y., Sheng, G.Y., Boyd, S.A., 2003. Sorptive characteristics of tetraalkylammonium-exchanged smectite clays. Clays Clay Miner. 51, 415-420.

Giles, C.H., Smith, D., Huitson, A., 1974. General treatment and classification of solute adsorptionisotherm. 1. Theoretical. J. Colloid Interface Sci. 47, 755-765.

Hayashi, A., Nakayama, H., Tsuhako, M. 2003. Adsorption of phenols by alkylamine-intercalated $\alpha-$ zirconium phosphate. Bull. Chem. Soc. Jpn. 76, 2315-2319.

Ide, Y., Ogawa, M., 2007. Interlayer modification of a layered titanate with two kinds of organic functional units for molecule-specific adsorption. Angew. Chem., Int. Ed. 46, 8449-8451.

Ide, Y., Nakasato, Y., Ogawa, M., 2010. Molecular recognitive photocatalysis driven by the selective adsorption on layered titanates. J. Am. Chem. Soc. 132, 3601-3604.

Ide, Y., Iwasaki, S., Ogawa, M., 2011. Molecular recognition of 4-nonylphenol on a layered silicate modified with organic functionalities. Langmuir 27, 2522-2527.

Jaynes, W.F., Vance, G.F., 1999. Sorption of benzene, toluene, ethylbenzene, and xylene (BTEX) compounds by hectorite clays exchanged with aromatic organic cations. Clays Clay Miner. 47, $358-365$.

Jordan, J.W., 1949. Organophilic bentonites. I. Swelling in organic liquids. J. Phys. Colloid Chem. 53, 294-306.

Kozai, N., Ohnuki, T., Muraoka, S., 1993. Sorption characteristics of neptunium by sodium-smectite. J. Nucl. Sci. Technol. 30, 1153-1159.

Lagaly, G., 1981. Characterization of clays by organic compounds. Clay Miner. 16, 1-21. 
Lawrence, M.A.M., Kukkadapu, R.K., Boyd S.A., 1998. Adsorption of phenol and chlorophenols from aqueous solution by tetramethylammonium- and tetramethylphosphonium-exchanged montmorillonite. Appl. Clay Sci. 13, 13-20.

Lee, J.F., Mortland, M.M., Boyd, S.A., Chiou, C.T., 1989. Shape-selective adsorption of aromaticmolecules from water by tetramethylammonium smectite. J. Chem. Soc. Faraday Trans. 85, 2953-2962.

Mercier, L., Detellier, C., 1995. Preparation, characterization and applications as heavy-metals sorbents of covalently grafted thiol functionalities on the interlamellar surface of montmorillonite. Environ. Sci. Technol. 29, 1318-1323.

Michot, L.J., Villiéras, F. 2013. Surface Area and Porosity. In Handbook of Clay Science, Volume 5B (Developments in Clay Science), Bergaya, F., Lagaly, G., Eds.; Elsevier: Amsterdam.

Nir, S., El-Nahhal, Y., Undabeytia, T., Rytwo, G., Polubesova, T., Mishael, Y., Rabinovitz, U., Rubin, B., 2006. In: Bergaya, F., Theng, B.K.G., Lagaly, G. (Eds.), Handbook of Clay Science; Clays and Pesticides, vol. 1. Elsevier, Ltd., pp.677.

Ogawa, M., Handa, T., Kuroda, K., Kato, C., Tani, T., 1992. Photochemical hole burning of 1,4dihydroxyanthraquinone intercalated in a pillared layered clay mineral. J. Phys. Chem. 96, 81168119.

Ogawa, M., Aono, T., Kuroda, K., 1993. Photophysical probe study of alkylammonium montmorillonites. Langmuir 9, 1529-1533.

Ogawa, M., Takahashi, M., Kato, C., Kuroda, K., 1994. Oriented microporous film of tetramethylammonium pillared saponite. J. Mater. Chem. 4, 519-523.

Ogawa, M., Kuroda, K., 1995. Photofunctions of intercalation compounds. Chem. Rev. 95, 399-438. 
Ogawa, M., Wada, T., Kuroda, K., 1995. Intercalation of pyrene into alkylammonium-exchanged swelling layered silicates - the effects of the arrangements of the interlayer alkylammonium ions on the states of adsorbates. Langmuir, 11, 4598-4600.

Ogawa, M., Kuroda, K., 1997. Preparation of inorganic-organic nanocomposites through intercalation of organoammonium ions into layered silicate. Bull. Chem. Soc. Jpn. 70, 2593-2618.

Okada, T., Ogawa, M., 2003. 1,1 '-dimethyl-4,4 '-bipyridinium-smectites as a novel adsorbent of phenols from water through charge-transfer interactions. Chem. Commun. 12, 1378-1379.

Okada, T., Morita, T., Ogawa, M., 2004. Adsorption Behavior of Phenol for Mono, Bis and Tris(2,2'bipyridine)nickel(II)- and Tris(ethylenediamine)nickel(II)-Saponite Intercalation Compounds from Aqueous Solution. Clay Sci. 12, 277-284.

Okada, T., Ogawa, M., 2004. p-Phenylenediammonium- smectites as adsorbents with colorimetric detection ability for phenols in water. Bull. Chem. Soc. Jpn. 77, 1165-1170.

Okada, T., Morita, T., Ogawa, M., 2005. Tris(2,2 '-bipyridine)ruthenium(II)-clays as adsorbents for phenol and chlorinated phenols from aqueous solution. Appl. Clay Sci. 29, 45-53.

Okada, T., Matsutomo, T., Ogawa, M., 2010. Nanospace engineering of methylviologen modified hectorite-like layered silicates with varied layer charge density for the adsorbents design. J. Phys. Chem. C. $114,539-545$.

Okada, T., Ide, Y., Ogawa, M., 2012. Organic-inorganic hybrids based on ultrathin oxide layers designed nanostructures for molecular recognition. Chem.-Asian J. 7, 1980-1992.

Okada, T., Seki, Y., Ogawa, M., 2014. Designed nanostructures of clay for controlled adsorption of organic compounds. J. Nanosci. Nanotech. 14, 2135-2147.

Seki, Y., Ogawa, M., 2010. The removal of 2-Phenylphenol from aqueous solution by adsorption onto organoclays. Bull. Chem. Soc. Jpn. 83, 712-715. 
Stein, A., Melde, B.J., Schroden, R.C., 2000. Hybrid inorganic-organic mesoporous silicates Nanoscopic reactors coming of age. Adv. Mater. 12, 1403-1419.

Tayama, S., Kamiya, N., Nakagawa, Y., 1989. Genotoxic effects of ortho-phenylphenol metabolites in CHO-K1 cells. Mut. Res. 223, 23-33.

Theng, B.K.G., 1974. The Chemistry of Clay Organic Reactions. John Wiley \& Sons, New York.

van Olphen, H., 1977. An Introduction to Clay Colloid Chemistry. Wiley-Interscience, New York.

Wei, Q., Nakato, T. 2006. Competitive adsorption of phenols on organically modified layered hexaniobate $\mathrm{K}_{4} \mathrm{Nb}_{6} \mathrm{O}_{17}$. Microporous Mesoporous Mater. 96, 84-92.

Xu, S., Sheng, G., Boyd, S.A., 1997. Use of organoclays in pollution abatement. Adv. Agron. 59, 25-62. 


\section{Table and figure captions}

Table 1. Adsorption parameters obtained from the isotherms.

Fig. 1. Structure of 2-phenylphenol (a) neostigmine (b), and octadecyltrimethylammonium (c).

Fig. 2. Nitrogen adsorption (filled symbols)/desorption (open symbols) isotherms for KA (a) and SA (b) before (circles) and after (squares) pillaring with $\mathrm{CONH}$.

Fig. 3. Adsorption isotherms of $2 \mathrm{PP}$ from water in the presence (open symbols) or absence (filled symbols) of sucrose on CONH-SA (squares) and CONH-KF (circles).

Fig. 4. Adsorption isotherms of $2 \mathrm{PP}$ on $\mathrm{C}_{18}$ TMA-KF from water in the presence $(x)$ or absence $(\circ)$ of sucrose.

Fig. 5. Efficiency of $2 \mathrm{PP}$ removal from aqueous sucrose solution on $\mathrm{C}_{18} \mathrm{TMA}-\mathrm{KF}(\times)$, CONH-SA (o), and CONH-KF ( $\square)$. 


\section{Table 1}

\begin{tabular}{llccc}
\hline & & $\mathrm{R}^{2}$ & $\begin{array}{c}\text { a (adsorption } \\
\text { constant) }\end{array}$ & $\begin{array}{c}\text { Ws (adsorbed amount of 2PP as } \\
\text { monolayer, g/g clay) }\end{array}$ \\
\hline \multirow{2}{*}{ CONH-KF } & without sucrose & 0.9818 & 20.0 & 0.041 \\
& with sucrose & 0.9856 & 20.7 & 0.041 \\
CONH-SA & without sucrose & 0.9552 & 36.1 & 0.062 \\
& with sucrose & 0.9327 & 45.3 & 0.067 \\
\hline
\end{tabular}


Fig. 1

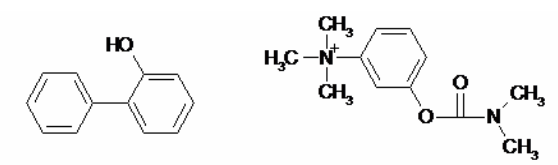

(a)

(b)

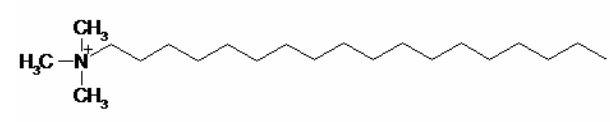

(c) 
Fig. 2
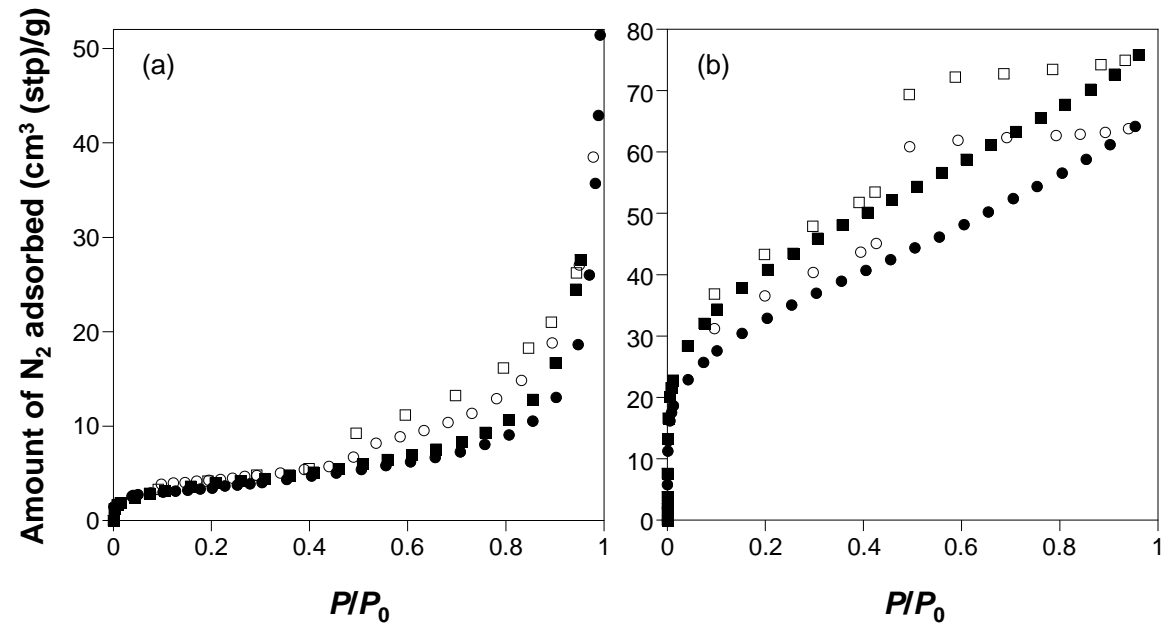
Fig. 3

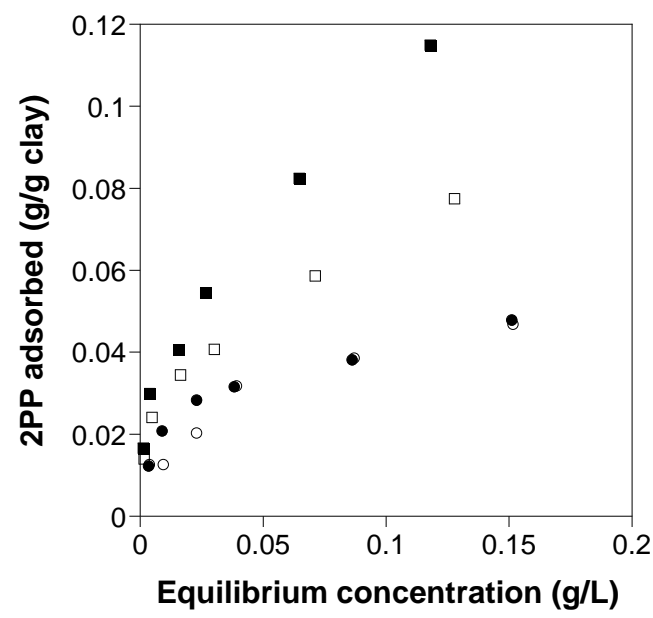


Fig. 4

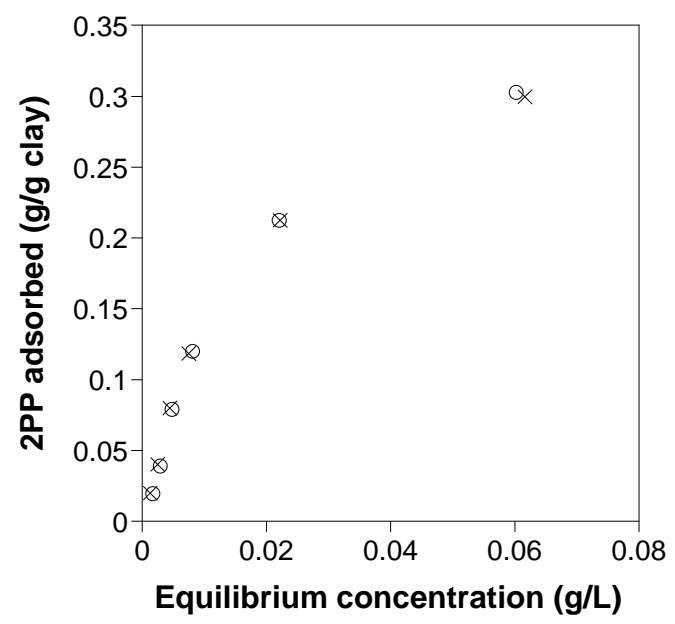


Fig. 5

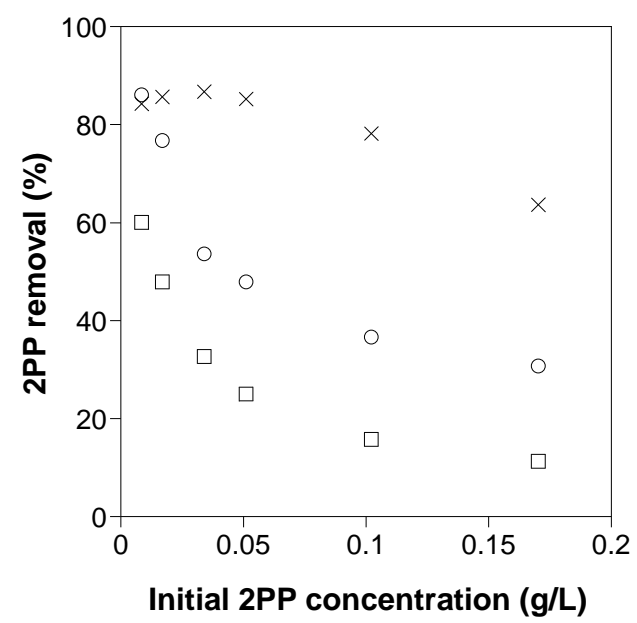

